\title{
APROXIMACIÓN A LAS REPRESENTACIONES DE LAS ÉLITES PAGANAS TARDOIMPERIALES SOBRE LA MAGIA, LA ADIVINACIÓN Y LA RELIGIÓN A TRAVÉS DE AMIANO MARCELINO.
}

\author{
GIULIANO DE CONTI RIVARA \\ Pontificia Universidad Católica de Valparaíso. Chile
}

\begin{abstract}
Postulamos que en la obra de Amiano Marcelino se observan al menos tres vías de comprensión diferenciadas para los fenómenos sobrenaturales: el conocimiento filosófico/científico que explica físicamente la realidad; el conocimiento que permite interpretar las señales de los dioses y sus actos en el mundo y un conocimiento asociado a diversas prácticas mágicas.
\end{abstract}

Palabras clave: Representación, Amiano Marcelino, magia, adivinación, religión, concepción de universo.

\section{AN APPROACH THROUGH AMMIANUS MARCELLINUS'EYES TO REPRESENTATIONS OF LATE IMPERIAL PAGAN ELITES IN TERMS OF MAGIC, DIVINATION, AND RELIGION}

Abstract: We suggest there are at least three different ways though which we can understand supernatural phenomena: the philosophical/scientific knowledge that provides a physical explanation of reality, the knowledge that allows the interpretation of gods'signs and actions in the world, and the knowledge that is associated to different magical practices.

Keywords: representation, Ammianus Marcellinus, magic, divination, religion, conception of the universe.

Recibido: 11.08.2014 - Aceptado: 25.09-2014 


\section{I.- El Problema: las representaciones de la magia y lo sobrenatural desde Amiano Marcelino}

Ste trabajo es un intento de comprensión de las estructuras de
representaciones de las élites romanas de la tardoantigüedad sobre la magia y lo sobrenatural, a partir de la obra de Amiano Marcelino ${ }^{1}$. Se pretende articular el cómo este grupo comprende el funcionamiento de su mundo a partir de las explicaciones y percepciones de lo mágico y lo sobrenatural. También, a través de este análisis podemos evaluar algunos postulados clásicos sobre la relación entre magia y religión (o su distinción) y de ciertos esquemas explicativos generales, como las nociones de antipatía y simpatía, Mana o de las cadenas verticales de influencia.

Concordamos con Narciso Santos Yanguas ${ }^{2}$, que Amiano Marcelino y al menos parte de las elites paganas contemporáneas comparten la representación de su mundo como uno en el cual las fuerzas sobrenaturales siempre están actuando en su vida cotidiana, un universo activo. Desde esta perspectiva, postulamos que Amiano Marcelino permite conocer al menos tres vías de comprensión diferenciadas, pero que también pueden encontrarse entremezcladas, para los fenómenos sobrenaturales o excepcionales: el conocimiento filosófico/científico que explica físicamente la realidad; el conocimiento que permite interpretar las señales de los dioses y sus actos en el mundo (aruspicina, astrología, libros de profecías, por ejemplo) y un conocimiento asociado a diversas prácticas mágicas en las cuales el ser humano controla parte de estas fuerzas sobrenaturales para sus fines.

Para lograr lo planteado y demostrar el punto, procederemos en primer lugar, a establecer algunas nociones básicas sobre la magia y sobre las teorías de representación. Terminado esto, iniciaremos el análisis de la fuente en la búsqueda de las representaciones posibles. Las limitaciones de información

1 Para una información básica sobre el autor y su obra, véase: Castillo García, Carmen, Alonso del real, Concepción y Sanchez, Álvaro, (Traducción y edición) Amiano Marcelino, Historias I. libros XIV-XIX, Editorial Gredos, Madrid, 2010; Harto de Trujillo, MaLuisa, (traductor y editor) Amiano Marcelino, Historia, Editorial Akal, Madrid, 2002 y Santos Yanguas, Narciso, "El pensamiento historiológico de Amiano Marcelino". Estudios Clásicos XX (1976) 103-122.

2 Santos Yanguas, Narciso "Presagios, adivinación y magia en Amiano Marcelino", Helmantica 30, 1979. 
nos llevan sólo a contrastar pensamientos teóricos de áreas como la filosofía, el ocultismo y la religión del autor o de otros personajes referidos por él, con las prácticas mágicas relevadas, de tal forma de analizar prácticas sociales, conocimientos, cultos asociados y la visión personal de Amiano, considerando la aplicación de ciertos elementos teóricos de la magia. Por tanto, comentaremos tres tipos de fragmentos de la obra del antioqueno: los que refieren a prácticas mágicas, los que explicitan alguna construcción teórica sobre lo sobrenatural y aquellos que explican de forma físico/filosófica ciertos fenómenos naturales. Finalmente, a través del contraste y análisis de estas tres nociones, propondremos un cuadro de las representaciones de estas élites sobre la magia.

\section{II.- Las representaciones y la magia. Algunas aproximaciones teóricas}

Denise Jodelet asocia las representaciones sociales con imágenes condensadoras de significado, sistemas para la comprensión de la realidad, su interpretación y predicción relativa, categorías de clasificación de sujetos y objetos y teorías asociados a ello. "Es una forma de conocimiento social, derivada del sentido común, práctico, que pone en relación los psicológico y lo social, con el fin de comprender, dominar y comunicar el entorno de los individuos, relacionando algo con un alguien"3. En su producción interactúa un contenido que es moldeado por los sentidos que los sujetos le dan a su existencia, la posición social y relacional de éstos y los otros sociales, que da lugar a una ideología o mentalidad específica, que también se relaciona con las estructuras de dominación y culturas hegemónicas de una sociedad.

La generación de las representaciones sociales, a partir de los factores anteriores, ocurre en dos fases distintas: objetivación (en el cual los individuos o grupos seleccionan los elementos, los esquematizan y los dan por aceptados) y luego anclaje (incorporación a lo social de las representaciones, con posibles tensiones, conflictos, alteraciones y rechazos). Es un proceso complejo de construcción/producción (considera las ideas, su soporte físico y su organización textual), recepción/interpretación (mediatizada por la posición de los actores en la sociedad y por las formas de lectura) y circulación de este

3 Jodelet, Denise, "La representación social: fenómenos, concepto y teoría". En: Moscovici, Serge (Ed.). Psicología social. Tomo II, Pensamiento y vida social, psicología social y problema social. Editorial Paidós. Barcelona. 1984, 472. 
tipo de conocimientos ${ }^{4}$.Por tanto, es una noción que permite definir el tipo de conocimiento que estamos intentando reconstruir, pero proviene de la teoría de la psicología social, por lo que es un concepto cognitivista, y sus formas de investigación están bastante lejos de las posibilidades que dan las fuentes ${ }^{5}$. Así, lo incorporamos como una definición que clarifica nuestro objeto de estudio y el lenguaje que utilizamos, pero del cual sólo podremos extraer algunos referentes metodológicos limitados: este trabajo se estructurará sobre la comparación de los fragmentos de explicaciones asociadas a la comprensión de lo sobrenatural que da nuestro autor, ya sean propias de él o representadas por él en su texto, su relación con algunas corrientes filosóficas y científicas sobre los fenómenos naturales y mágicos que circulaban contemporáneamente a las que podría haber accedido el autor y finalmente, las referencias a ciertas prácticas sociales asociadas al problema, nuevamente mediatizadas por el autor.

Dejando claro este punto, toca referirse a la magia. Una de las primeras teorías generales sobre la magia, fue propuesta por el antropólogo del S.XIX, James Frazer, que identifica el acto mágico con las nociones de simpatías y antipatías, una concepción supuestamente primitiva, por la cual, los seres y objetos del universo están unidos por contigüidad o similitud. Así, las partes de los objetos con sus todos, los conceptos y sus significantes, estarían unidos indisolublemente y por ello, son susceptibles de ser afectadas por determinadas prácticas: «Lo semejante produce semejanza; las cosas que han estado en contacto y han dejado de estarlo continúan actuando las unas sobre las otras, como si el contacto persistiera. ${ }^{6}$. Esta teoría ha mantenido estos conceptos como claves de la conceptualización sobre la magia ${ }^{7}$, pero ha sido criticada en

4 Para una visión más profunda de estos problemas referentes a la circulación de las ideas y la construcción de visiones de mundo, véase: Chartier, Roger, El Mundo como Representación. Historia Cultural: entre práctica y representación. Editorial Gedisa, Barcelona, 1992.

5 Para una interpretación de las posibilidades historiográficas de esta noción en la historia cultural, véase Ruiz Guadalajara, Juan Carlos, "Representaciones colectivas, mentalidades e historia cultural: A propósito de Chartier y el mundo como representación", Relaciones. Estudios de Historia y Sociedad, La Representación en las Ciencias Sociales, Vol. XXIV, 93, 2003, 17-49.

6 Citado en Mauss, Marcel. "Esbozo de una teoría de la magia", en: Sociología y Antropología, editorial Tecnos, Madrid, 1999.

7 Para una visión crítica de estos conceptos, véase: Collins, Derek, Magic in the Ancient Greek World, Blackwell Publishing, Oxford, 2008; Martín Hernández, Raquel, El 
dos flancos: Según antropólogos contemporáneos ${ }^{8}$, por responder a la noción evolucionista y eurocéntrica de la "mentalidad primitiva", considerándola una práctica falsa y errada, y por otro estudioso clásico de la magia, M. Mauss, que considera que la magia puede ser conceptualizada con mayor generalidad y precisión si se deja reducido a un elemento parcial la noción de simpatía9. Para este autor, la magia tiene 3 esferas diversas que la explican: el mago, como personaje identificable y con cualidades particulares reconocidas socialmente (normalmente míticas), las representaciones que se asocian a la magia en general y las formas rituales que se realizan, que demuestran una relativa eficacia. En asociación a las representaciones, la magia se sustentaría en determinadas abstracciones conscientes (si son teorizadas) o inconscientes, que actúan como leyes, tales como la contigüidad, la similitud y la contrariedad. Es decir, nociones que se remontan a la idea de simpatía y antipatía. También hay un conjunto de representaciones de corte concreto, que se refieren a las propiedades de ciertos objetos, a los que la práctica social ha atribuido cualidades mágicas que son reconocidas y transmitidas de generación en generación. Estos tres factores (mago, representación y rito) representan un todo multiforme, que se asociaría a las ideas de ciencia y de religión. A la primera, por cuanto la magia responde a un conjunto de prescripciones dadas por verdaderas aplicables sobre la naturaleza, y sobre la religión, por cuanto se sustenta en creencias sociales asociadas a determinados ritos. Aún así no se confunde con ellas. Llegados hasta acá, el autor demuestra que lo más específico de la magia está en el concepto de Mana (en Grecia se asocia a Dynamis), que significa la fuerza, la cualidad y el sustrato que hace posible el acto mágico. El mana es una categoría reconocida socialmente que permite calificar los objetos del mundo, que se derivaría de las necesidades de la sociedad: se cree en el mago y en la magia a priori, hay una sugestión colectiva ante el rito mágico no sólo porque sus actos le permitan apoyar esa sugestión, sino porque existen deseos y expectativas a los que se espera que se responda con el rito mágico. Así, la magia estaría más cerca de un conocimiento

orfismo y la magia, Universidad Complutense de Madrid, Madrid, 2006 y García Tejedor, Esther C., Formas marginales de la racionalidad en las ciencias ocultas, Departamento de Filosofía de la Facultad de Filosofía de la U.N.E.D. 2002.

8 Para una crítica al concepto de magia en general, véase Otto, Bernd-Christian, Stausberg, Michael (Eds.), Defining Magic. A reader, Equinox Publishing, Sheffield, 2013.

9 La síntesis teórica establecida aquí bebe de Mauss, Marcel. "Esbozo de una teoría de la magia", en: Sociología y Antropología, editorial Tecnos, Madrid, 1999. 
técnico-científico que de uno religioso, por cuanto seria una especie de técnica en la cual se realizan las aspiraciones individuales y sociales a través de la explotación de imágenes y creencias particulares, insertas en una idea particular del mundo. A medida que sistematizan los conocimientos mágicos, nos iríamos acercando más a la ciencia y se va perdiendo la experiencia mística social que la acompañaba antes, pues la participación de la sociedad en las concepciones que la sustentaban se va diluyendo ante las fórmulas establecidas de antemano por los magos. En esta lógica explicativa, creemos particularmente útil la definición de G. Luck ${ }^{10}$, que considera a la mágica como una técnica que permite imponer la voluntad humana sobre la naturaleza u otros hombres a partir de poderes suprasensibles localizados en nuestra alma o más allá del hombre.

El problema de las relaciones de la Magia con otras esferas del conocimiento y prácticas sociales ha sido un debate corriente: por un lado se postula que religión y magia proponen que existen fuerzas sobrenaturales en el mundo que afectan a los seres humanos, por otro, se intentan distinguir cualidades particulares. De forma general, se considera ${ }^{11}$ que la magia actúa más bien sobre fuerzas impersonales, mientras la religión tiende a relacionarse con seres conscientes y personalizados (esto ha sido criticado por su tono cristiano), también, que la religión es más bien social y general, y la magia es más bien privada e individual (incluso considerada peligro social). Finalmente, se consideran diferencias de actitud: el mago pretende la coacción de las fuerzas que invoca, la religión en cambio se relaciona con la plegaria, el sacrificio y la súplica. Este conjunto de distinciones, si bien puede ser operativas, han sido criticadas como demasiado generalizadoras y derivadas de prejuicios modernos y no de las lógicas internas de las sociedades antiguas, que muchas veces no distinguían estas esferas y usaban un vocabulario común. Aún así, considero que para el siglo IV, donde el cristianismo se consolidó como religión de estado, pueden tener alguna validez.

También existen otros elementos a considerar, como que por ejemplo, se tiende a clasificar como mágicos aquellas creencias religiosas que no

10 Luck, Georg, Arcana Mundi: Magic and the Occult in the Greek and Roman Worlds. A Collection of Ancient Texts, Baltimore. John Hopkins University Press. 2006, 33.

11 Para una síntesis de este debate, Véase Luck, Op. Cit, 33-95 y también Gil, Luis, "Medicina, religión y magia en el mundo griego", Cuadernos de filología clásica: Estudios griegos e indoeuropeos, $\mathrm{N}^{\mathrm{o}} 11,2001,179-198$. 
se comprenden o están fuera de los cultos oficiales como construcción desde el poder para caracterizar formas culturales subalternas o bien ya no hegemónicas ${ }^{12}$. No por nada el concepto de magia deriva de magoi, en referencia a los sacerdotes persas/caldeos que a los ojos de los griegos de época clásica, realizaban prácticas que no eran homologables a su religión. O por eso mismo, en el siglo IV d.C, a partir de una legislación que penaba ciertos ritos que podían atentar contra el orden social (magia "negra") muchas prácticas paganas fueron catalogadas de esa forma y penadas por la ley. Algunos explican esta ambivalencia entre religión y magia en lo que se ha llamado un proceso de superstización, en el cual rito y prácticas religiosas de un momento, al perder su vigencia y sentidos sociales, desnaturalizándose la teoría y visión de mundo que las sostiene, se van reduciendo cada vez más a la esfera de lo privado, de lo oculto y son despreciadas como falsas por las élites intelectuales y consideradas peligrosas por las élites políticas ${ }^{13}$.

Una de las formas más elaboradas de práctica mágico-religiosa en boga hacia los siglos III y IV d.C., es la llamada Teurgia ${ }^{14}$, una práctica filosóficomágica iniciática para la búsqueda de la salvación del alma del practicante. En su forma vigente en el siglo IV, une nociones derivadas del neoplatonismo Plotiniano, creencias egipcio-babilónicas derivadas de textos como los oráculos Caldeos y mitos cosmogónicos derivados del hermetismo, por lo que es fruto del sincretismo cultural y pérdida de sentido de la religión tradicional griega del mundo helenístico. Por medio de una concepción del mundo que concibe la unión de los elementos del universo en cadenas de simpatía ascendentes hasta el ser creador mismo, una práctica ascética y de estudio severas y determinados rituales, se espera que el practicante alcance la Gnosis y su alma ascienda en la contemplación y unión con el Uno. En su forma ritual más cercana a la magia, buscaba la atracción de poderes divinos al mundo terreno, de tal forma de animar estatuas que eran útiles para la profecía y para ejercer ciertas funciones más o menos mundanas en la tierra y también generar una interconexión entre el alma del practicante y la divinidad, como una especie de médium moderno. Este tipo particular de magia es relevante, porque justamente dentro del círculo

12 Esta teoría ha sido clasificada como sociológica. Para una revisión crítica, véase García Tejedor, Op.Cit, 37-56.

13 García Tejedor, Op.Cit. 637-656.

14 Para una introducción al tema, véase Dodds, E. R., Los griegos y lo irracional. Madrid: Alianza Editorial, 1997, 265-283. 
del emperador Juliano, del que participaba nuestro autor, había personajes versados en esta creencia ${ }^{15}$.

\section{III.- Prácticas mágicas, teorías sobre la adivinación y explicaciones de fenómenos naturales en Amiano Marcelino.}

Hechos los preámbulos teóricos, analizaremos algunos de los casos de prácticas que podríamos clasificar como mágicas descritas por nuestro autor. Nos interesa destacar tres puntos: Tipo de prácticas (en cuanto a ritual y aplicación), concepto bajo el cual es definido y postura de Amiano respecto a las mismas. Si es posible, además identificar algunos elementos explicativos de esas prácticas, ya sea desde los actores, como desde la teoría de la magia anteriormente explicada. En primer lugar, es importante considerar que la legislación imperial consideraba criminal este tipo de prácticas. Desde 357, Constancio II promulgó un conjunto de edictos, condenando a muerte a hechiceros, arúspices, astrólogos, caldeos, adivinos, intérpretes de sueños y brujos comunes ${ }^{16}$, y más tarde, Valentiniano I, si bien eximió de esta penas a los cultores aceptados por el paganismo oficial (los arúspices), si condenaba a muerte a quienes profirieran imprecaciones malignas, rituales mágicos, sacrificios necrománticos o consultara a astrólogos y matemáticos ${ }^{17}$.

A modo de análisis tipológico, podemos distinguir algunos tipos de prácticas mágicas referidas por Amiano, basándonos en la forma en cómo el autor las refiere: Por un lado, algunas prácticas de tipo terapéutico, realizadas para evitar ciertas enfermedades o aliviar síntomas, que quedan más bien llevadas al campo de la medicina. Por otro lado, algunas prácticas necrománticas para fines adivinatorios, prácticas de maleficio y uso de pócimas, que podríamos definir como perturbadores del orden social. Y finalmente, una práctica de adivinación, que se asoció a una conspiración para derrocar a Valentiniano.

15 Por ejemplo, el filósofo Máximo de Éfeso, mentor de Juliano. Véase Alsina, José, El neoplatonismo, síntesis del espiritualismo antiguo, Barcelona, Ed. Anthropos, 1989, 86-87.

16 Para análisis sobre esta legalidad, véase, Santos Yanguas, Narciso, Op. Cit., 43, Collins, Op.cit., 163-164, Dickie, Metthew, Magic and Magicians in the Greco-roman World, London and new York, Routledge, 2003, 242-247. El fragmento sintetizado pertenece al Código Teodosiano, 9.16.

17 Santos Yanguas Op.cit., p. 44, Códice Teodosiano 9, 16. 
En XVI, 8, 1-2, se relata que en un campamento del Augusto Constancio II, hacia 357 , se desató un conjunto de acusaciones, que podían llevar a la muerte a quien usara para evitar el dolor "uno de esos encantamientos de vieja, también admitidos por la medicina". No tenemos más informaciones, pero el concepto de incantamentum (en griego Épodos) hace referencia al de la recitación o canto realizado con una función reconfortante, de eliminación del dolor, además de ser funcionar como acto curativo y apotropaico. Se le ha identificado también como parte de rituales iniciáticos ${ }^{18}$. Este fragmento nos informa, además del uso de salmodias contra el dolor, que es posible considerarlas médicas y que nuestro autor, utilizando esa aclaración, rebaja su condición de criminalidad. Es decir, podemos afirmar que dentro del conocimiento culto, era útil y aceptable que antes problemas de salud, acudir a alguna especie de curandera ${ }^{19}$.

Amiano también considera ciertas prácticas que desde el hoy calificaríamos de mágicas como criminales y negativas. En general, aquellas prácticas que atenten contra otros individuos, el orden político (donde se confunden con el crimen de lesa majestad), se relacionen con el mundo de los muertos o con sustancias dañinas, son referidas de forma negativa. Así por ejemplo, tenemos la persecución judicial que hace Aproniano, prefecto de Roma, en 342 (XXVI, 3. 1-6), a los magos, relatando dos procesos, uno a un auriga y otro a un senador, por enseñar respectivamente a un hijo y a un esclavo este tipo de conocimientos. Lo relevante en esto, además de considerar Amiano estos procesos como justos, es la utilización de conceptos del autor: los magos son definidos como veneficos, terminología con la cual se denominaba en la legalidad republicana a los envenenadores, que en el lenguaje común se que se fue homologando al de magus luego del siglo II d.C. ${ }^{20}$. Se observa una carga negativa de la idea de mago y las enseñanzas condenadas son definidas como artes secretas, arcanas, prohibidas por ley y malignas. Notamos como Amiano evita la palabra Magus. De hecho, el antioqueno reserva la palabra sólo para su uso propio: referirse a los sacerdotes persas ${ }^{21}$, que son descritos de forma positiva

18 Martín Hernández Op. Cit., 101.

19 Para otros casos de magia terapéutica "inocente", véase Amiano XXIX, 2. 26-28 y XXIX, 12. 14.

20 Collins, Op. Cit. 149.

21 Para un análisis sobre este punto, Den Boeft, Jan, "Pure Rites, Ammianus on the magus", Drijvers, J.W., Hunt, David, (Eds) The Late Roman World and its Historian. Interpretating Ammianus Marcelinus, Londres y New York, Routledge, 1999, 183 - 
en XXIII, 6; como conservadores de una práctica y sabiduría religiosa pura y efectiva. Por tanto, para nuestro autor, un magus es un practicante religioso y los practicantes de otro tipo son rebajados de condición. Como hemos visto, o bien son inocentes ancianas que hacen encantamientos terapéuticos, o bien son personajes cuyo hacer es considerado maléfico, agresivo, ilegal y que debe ser justamente reprimido por la ley para conservar el orden imperial.

Finalmente, Amiano, en XXIX, 1 y XXIX, 2 nos relata cómo, en 372, fueron condenados por el crimen de lesa majestad diversos personajes que ostentaban cargos en la administración imperial, que habían predicho que Teodoro, notario de palacio, sucedería a Valente. La acusación, realizada por un acusado y torturado por veneficum, sostenía que los personajes lo habían realizado por medio de "formas detestables de adivinación" (detestandis praesagiis). Se les acusó que eran expertos en adivinación que utilizando artes secretas (secreti sartibus) descubrieron al sucesor imperial. Avanzado el proceso (donde Amiano resalta la pérdida de la justicia en Valente), se les muestra el trípode de laurel con el cual realizaron el acto adivinatorio, descrito como semejante al de Apolo Délfico y que fue consagrado con fórmulas secretas y rituales varios. Según el relato, colocado en una casa purificada con perfumes árabes, encima tenía un plato metálico con las letras griegas grabadas. Un oficiante, vestido y calzado de lino, con una cinta en la cabeza y con ramas de un árbol propicio invocaba con formulas rituales a la divinidad promotora de las profecías. Este oficiante que hacía como sacerdote, balanceaba un anillo suspendido en un hilo también consagrado por rituales secretos. El anillo se detenía en las letras y respondía en versos heroicos, de forma similar a como responde la pitia o el oráculo délfico de los Brachidas El ritual indicó a alguien cuyo nombre comenzara por "Theo" como sucesor de Valente, por lo que los perpetradores identificaron a Teodoro como el sucesor. Se termina el relato con unos versos: según Amiano, son unos muy conocidos que indican que el escudriña el futuro adelanta su muerte, pero que también sirvieron de vaticinio de la muerte del emperador y sus jueces, cosa que Amiano confirma más tarde en XXXI, 14. 8-9. Finalmente, todos los involucrados fueron torturados y muertos.

El pasaje es interesante porque explica en detalle una práctica mágica de adivinación, permitiéndonos concluir no sólo la visión del autor sobre el tema, sino los fundamentos de ésta. Amiano utiliza siempre palabras que

190. 
evitan el concepto magia como tal y tienden a tener connotación negativa: artes secretas, formas detestables de adivinación, fórmulas secretas, aunque no deja de transmitir la supuesta pericia de los oficiantes.

El ritual en sí mismo, en todo caso, parece más bien una especie de simulación de las prácticas cúlticas oficiales de los oráculos délficos. Si bien el secretismo del ritual y los fines del mismo lo acercan a las nociones de magia que Amiano y la legalidad manejan, no deja de ser interesante como se establecen constantes paralelismos con el acto religioso aceptado: se usa un trípode, idéntico al de la Pitia, hecho de laurel, el árbol sagrado de $\mathrm{Apolo}^{22}$, se reciben las respuestas en versos estructuralmente idénticos a las respuestas del dios. Además, se agregan el conjunto de prescripciones mágicas no especificadas que incluyen encantamientos, salmodias y consagraciones (carmina) secretas y el uso de purificaciones con aromas, utensilios y vestimentas de materiales específicos. La lógica de ritual la podemos considerar como una imitación del ritual délfico, en el cual en vez de que el dios posea a la pitia, se atrae a divinidades proféticas no identificadas (Apolo?) a responder las preguntas mediante lo nosotros llamaríamos una ouija. Por tanto, podemos aplicar la noción de Frazer de analogía o imitación y también de simpatía, en cuanto se espera que los elementos rituales délficos, las consagraciones y preparaciones rituales específicas, por sus cualidades asociadas al dios/dioses, permitan la obtención del oráculo. La estructura de imitación y simpatía a la que se apela, creemos puede ser puesta en relación con la idea de cadenas verticales de influencia ${ }^{23}$, que permiten relacionar a las divinidades particulares entre sí con los astros, constelaciones, plantas, animales, minerales y substancias, relevando la unión y presencia de lo sacro en todo el universo, en un orden jerarquizado.(En algunas cosmogonías asociadas al Egipto helenizado se les relaciona además con la divinidad original y creadora del mundo, todo derivado de un mito cosmogónico) así, la purificación, los vestuarios, los elementos consagrados, las ramas y el trípode de laurel, aparecen orientadas para acceder a la "energía" e influencia de las divinidades de la profecía.

22 Sobre el ritual oracular, véase Dodds, E.R. Op.cit, 75-81. Según García Tejedor, Op.Cit. 121, el laurel se asocia a lo ígneo, al encendido del fuego, y más adelante veremos cómo es al sol que se atribuye el éxtasis de la pitia.

23 Sobre esta noción teórica, véase: García Tejedor, Op. cit. 109-133. 
Además, al terminar el relato, se presenta a los adivinos como conscientes del destino funesto que se crearon y se hace referencia a las furias y a la venganza de los dioses, que también caerán sobre el emperador injusto, haciéndose un nexo con el sistema religioso-teológico que algunos han identificado en Amiano ${ }^{24}$.

Amiano no parece dudar de la culpabilidad de los personajes y de devaluar sus acciones mágico/religiosas a través de los conceptos que usa, pero también no deja de lamentarse como este evento terminó en una sangrienta persecución que castigó injustamente a muchos honorables y dio poder a los aduladores y calumniadores de la corte imperial, y que además, luego dio lugar a injustos procesos y condenas por veneficum que envolvieron a Oriente. Si bien podemos decir que el historiador rechaza este tipo de hechos políticos, la evaluación del caso (y por ende de la práctica mágica contenida en él) debe ser relacionada con un tópico usual en nuestro autor: el de la moderación ${ }^{25}$. En otro fragmento (XIX, 12, 17-18), se nos dice como deberían aplicarse este tipo de legislaciones represivas: luego de justificar la existencia de la protección de la majestad del emperador y referirse a las leyes Cornelias, sugiere seguir a Cicerón, que prefiere perdonar a castigar y hacer así los juicios "serenos e imparciales".

Pero no sólo procesos judiciales contra la magia nos habla Amiano Marcelino, existen numerosos pasajes en que se manifiesta la acción sobrenatural en la historia y una serie de prácticas aceptadas en la religión oficial para la lectura de esas intervenciones. Portentos, presagios, señales y su interpretación por medio de ciertos expertos o prácticas son recurrentes. En este respecto, consideramos, junto con Jason P. Davies ${ }^{26}$, que este tipo de referencias permiten deducir modelos religiosos derivados de un programa de restauración de la religión imperial, adecuado al tiempo en que vivía el antioqueno. Por tanto, afirmamos que en los contextos oficiales, la lectura de presagios y similares acciones por parte de oficiantes reconocidos, cabría en

\section{Véase infra.}

25 Esta idea es sostenida en Woodman, A.J (ED.). The Cambridge Companion to Tacitus. Cambridge, Cambridge University Press, 2009.

26 Davies, Jason P. Rome`s Religious History, Livy, Tacitus and Ammianus on their Gods, Cambridge, cambridge University Press, 2004. en particular págs. 237-240 y para su descripción, págs. 252-282. 
la calificación de "práctica religiosa", respondiendo a algunas cualidades que distinguirían a la magia de la religión ${ }^{27}$, como la de ser de un análisis posterior a la acción activa de la divinidad y considerarse una práctica pública y centrada en lo colectivo, que se percibe como constitutiva de la tradición propia.

Dirigiremos nuestra atención a los casos que consideramos más relevantes. Para comenzar, referiremos algunas referencias directas a presagios y su interpretación ${ }^{28}$ :

A comienzos del último libro del texto, se hace una larga descripción sobre los presagios del asesinato de Valente y la invasión goda (XXXI, 1 1-5). El capítulo comienza con una referencia mítica: la rueda de la fortuna armaba a Belona y a las furias para producir desastres en Oriente, que fueron presagiados con claridad por augurios y portentos. Además de las muchas predicciones exactas de augures y arúspices, se nombran perros que saltaban, cantos lastimosos de aves, un sol poco luminoso, que el pueblo de Antioquía que pedía se "quemara vivo a Valente"o sus construcciones, adelantando la muerte bajo el fuego que tendrá el emperador, que la imagen fantasmagórica de rey de Armenia y las tristes sombras de los condenados en el asunto de Teodoro, aparecíanse en los sueños de la población cantando lúgubremente, una ternera muerta por un corte en su cuello (señal de funerales públicos se explica) y una inscripción desenterrada en Constantinopla que indicaba la invasión que se avecinaba. Primero debemos destacar la presencia de profesionales en este tipo de prácticas, que anunciaron por su cuenta los sucesos ${ }^{29}$. Luego de ello, relata una buena cantidad de hechos fantásticos, que se asocian a diversas fuentes

27 Con esto no decimos que esta distinción sea siempre útil y clarificadora de la mentalidad antigua en general, porque se le ha acusado con razón de cristianizante o al menos, occidentalizante, pero desde Amiano mismo se trasluce este tipo de distinciones entre una práctica religiosa más bien oficial y otra práctica que caería dentro de la noción de veneficum.

28 Para un panorama de este tipo de referencias, véase, además de las analizadas en este trabajo, Amiano Marcelino, XIX, 12. 1-18, (sobre unas acusaciones de lesa majestad en asociación a oráculos),XXI, 14 (Presagios de la muerte de Constancio II), XXII, 1.(Prácticas adivinatorias por Juliano y sus expertos para conocer la situación de Contancio II), XXII, 12, 6-8 (Prácticas adivinatorias y propiciatorias realizadas por Juliano en la antesala de su campaña persa) y XXIII, 1. 5-7 (Presagios funestos contra la expedición persa de Juliano).

29 Véase infra. 
de adivinación aceptadas por el autor y que son referidas en otros momentos y teorizadas: conductas animales (perros y aves), luminosidad del sol, el vox populi, apariciones fantasmagóricas varias, inscripciones que aparecen, que indicarían el porvenir. En la concepción del antioqueno, la divinidad siempre envía señales a los hombres sobre el suceder, sobre el camino de la fortuna y el fatum y es clave para los hombres su correcta interpretación para regular sus conductas. Es un universo activo, que interviene siempre en el quehacer histórico humano. La importancia explícita que Amiano da a la correcta interpretación de las señales (y por ende de una conducta religiosa acorde) se denota con el pasaje XXIII, 5. 8-14. En 362, estando Juliano en Mesopotamia durante su campaña contra Persia, se produce un debate entre los arúspices etruscos y algunos filósofos, discípulos del neoplatónico Máximo, sobre la interpretación de algunos signos. Primero, se capturó un león de singular tamaño, hecho que dio falsa confianza al emperador, a pesar de ser ambiguo. Los arúspices, sacando sus libros de adivinación, mostraron al emperador que era una señal de que no debía continuar su campaña. Ante esto los filósofos, interpretaron la señal como que indicaba la victoria sobre el enemigo y un regreso seguro. Más tarde, una nube extraña y poderosa se formó, cubriendo el sol y descargando un rayo que mató a un soldado y a dos caballos. Los expertos siguieron insistiendo en que se desistiera la campaña, porque era un rayo "consiliario" y había matado a animales de combate y a un soldado destacado. Además, sus libros prescriben el dirigirse en la dirección del rayo. Los filósofos desestimaron la interpretación, ya que lo consideraron un fenómeno celeste natural ${ }^{30}$ (masa de aire emanada desde el éter) y que era un indicio positivo. El emperador no retrocedió en su proyecto, cosa que Amiano lamenta, ya que en su deseo de seguir las interpretaciones favorables a su causa, acabó consumando su propia muerte ${ }^{31}$. En el pasaje descrito, si bien el autor no termina su juicio, está claro que hay una preferencia por los expertos tradicionales y aceptados en la práctica religiosa estatal: los arúspices etruscos, que ante la poca atención que reciben, utilizan como referencia no sólo sus saberes y experiencia, sino también una literatura especializada, que podemos suponer de origen tradicional y que refrenda sus interpretaciones. Está claro, los arúspices son una autoridad reconocida en estas temáticas, y se tiende a ver con malos ojos el que personas no expertas cumplan

30 Sobre las explicaciones naturalistas en la obra de Amiano, véase infra.

31 Davies, op.cit, 249-252, comenta este punto, considerando que Juliano no habría cumplido el cultus deorum ideal de Amiano, justamente por su mala recepción de las correctas interpretaciones de los arúspices. 
esos roles. De hecho, en XXII, 12, 6-7, Amiano no sólo se lamenta de la falta de moderación sacrificial de su emperador favorito y sus consecuencias negativas para el erario público y la disciplina militar, sino que a su alero, "se permitía que todos los que practicaran el arte de la adivinación ya fueran inexpertos o conocedores de él, consultaran la respuesta de los oráculos y de las entrañas, que en ocasiones revelan el futuro". En la misma línea, en XXV, 4. 17, en el elenco de defectos del emperador Juliano, considera que ponía demasiada atención a los presagios y que su culto era más supersticioso que verdaderamente religioso. Notamos que, además de la advertencia de que "con las señales de los dioses no se juega"declarando explícitamente que la verdadera observancia de los cultos estaba lejos del exceso de prácticas adivinatorias y sacrificios que atribuidas a Juliano, también se nota como los círculos imperiales prestaban bastante atención a este tipo de sucesos, existiendo diversas formas de acceder a ellos, de explicarlos e interpretarlos.

Finalmente, para acabar con las referencias a estas prácticas, quisiéramos referirnos a la aparición de un portento monstruoso en Antioquía, (XIX, 12. 19-20), un bebé deforme con dos cabezas, dos bocas, cuatro ojos y otras deformidades habría nacido hacia 359. Amiano no sólo lo interpreta como un signo de que el estado se estaba deformando, sino que además se lamenta porque este tipo de señales son ignoradas y las expiaciones que antiguamente se realizaban, (necesarias para renovar la paxdeorum, que es un concepto que poco usa Amiano), ya no existen. ¿Que más claro indicador de la importancia político-religiosa que Amiano otorga a la lectura de las señales del universo?

Ahora bien, bajo el riesgo de simplificar el complejo análisis de Davies $^{32}$, nos limitaremos a consignar que Amiano no era un fatalista: El fatum o destino, correspondería a los hechos que ocurren. Su desarrollo estaría marcado por la acción de los dioses (numen, divinidad), que a través de la fortuna variable o de la nemesis, manejarían el destino de los hombres usando como canon la noción de justicia. Por tanto, la iustitia hace responsable a los hombres de su destino (en particular al emperador del destino del imperio) y por lo mismo, adquieren un sentido más profundo las constantes referencias a presagios, portentos, señales, arúspices, adivinos, oráculos de la fortuna, al destino, las furias y también las lamentaciones recurrentes de la injusticia de los emperadores o sus delegados, ejemplificadas magistralmente en los juicios

32 Ídem. 
contra la lesa majestad y el “ocultismo”. Lo que podríamos ver cómo procesos dados por legítimos por Amiano, se transforman una y otra vez en paradigma de la injusticia y del abuso, signos de la decadencia imperial.

Ahora bien, en nuestra tarea de la comprensión de las representaciones en tanto sistemas de creencias, no basta indagar las prácticas y las concepciones inmediatas del antioqueno sobre esos eventos, también es relevante explicar lo que podríamos llamar una "teoría" sobre estos temas, la reflexión consciente de Amiano y otros que a través de él se expresan.

Amiano realiza algunos excursos que, integrando saberes provenientes de diversas tradiciones de pensamiento, explican diversos fenómenos naturales y sobrenaturales. El análisis que haremos a algunos de ellos, permite notar el eclecticismo de nuestro autor, que utiliza a filósofos y pensadores variados y, por sobre todo, el cómo integra pensamientos "científicos" de corte naturalista vigentes en su tiempo, con otras explicaciones filosóficas que podríamos calificar de "místicas" y religiosas en un todo. Para explicarlo, fuera de recordar que las fronteras de la ciencia, la religión, la medicina y la magia eran bastante permeables en la antigüedad, porque las estructuras de saber religioso y científico no eran canónicas ni rigurosas incluso en las élites ${ }^{33}$, podemos insertar la noción de planos o niveles de análisis que postula Davies ${ }^{34}$ para la religión antigua: en general, los sistemas de conocimiento y representación religiosos son complejos y es según la situación a que herramientas cognitivas se recurren y que tipo de respuesta se ofrece.

Refiriéndose en XXI, 14. 3-5 a las señales de su muerte que observó Constancio II, se nos dice que el emperador habría dejado de ver la imagen borrosa que sería su genio protector, deduciendo así que su muerte se acercaba. Luego de esto, se nos informa que varios teólogos (theologi) dicen que cada hombre tiene un genio que intenta regir nuestros actos en consonancia con las leyes del destino. Para reforzar la idea con autoridades, refiere que oráculos se

33 Phillips, C.R. III, “Nullum Crimen sine Lege: Socioreligious Sanctions on Magic", Faraone, Christopher, Obbink, Dirk, (Eds.) Magika Hiera, Ancient Greek Magic \& Religion, New York y Oxford, Oxford University Press, 1991, 260-269, propone esa consideración para evaluar la legalidad contra la magia y su aplicación en la antigüedad.

34 Davies, Op.cit, 1-17. 
han manifestado de acuerdo, cita al comediógrafo Menandro, refiere la Homero y también que se dice que toda serie de personajes ilustres sobresalieron apoyados por sus genios (Pitágoras, Sócrates, Numa, Escipión el Africano, Mario, Octavio, Hermes Trismegisto, Apolonio de Tiana y Plotino). Finalmente, refiere a algunas nociones Plotinianas: se dice que este neoplatónico demostró la unión de nuestra alma a los genios y cómo con una vida pura y alejada del pecado, podemos acceder a las verdades esenciales a través de ellos. Notamos la referencia a unos anónimos teólogos, a la literatura y a un vago "se dice" que relaciona a los genios con personajes diversas, incluyendo el mítico Hermes Trismegisto, al que los herméticos atribuían sus creencias y prácticas filosóficomísticas (identificados como un antecedente del neoplatonismo ${ }^{35}$ ). Remata el asunto con un conocimiento escueto de las ideas Plotino. Es sabido el fuerte influjo neoplatónico en el círculo de Juliano el apóstata y es necesario destacar que desde él se pueden extraer algunas nociones sobre la estructura del universo sagrado: las enseñanzas de Plotino no sólo explicaban la génesis del universos y sus partes, sino que también postulaba un proceso de estudio, interiorización, purificación y retiro que permitía al alma alcanzar el conocimiento supremo y su salvación ${ }^{36}$, idea que de alguna forma expresa también Amiano en relación a los genios.

El excurso sobre la adivinación comienza como una defensa de Juliano, ante quienes consideran que utiliza artes malignas para conocer el futuro, intentando demostrar que es un conocimiento útil y digno de hombres prudentes. Es decir, a la par que se evita la calumnia al emperador, se revalida la adivinación como arte útil y se subentiende, legítimo. Por tanto, se intenta alejar la adivinación de los calificativos utilizados para referirse a la magia en otras partes del texto. Debemos notar eso sí, que este excuso es una defensa de Juliano en este aspecto, pero que Amiano no aborda el problema de la teúrgia en el círculo del emperador, ya que como no comparte del todo los usos adivinatorios del emperador y su cosmovisión, su posición le impide defenderlo en este aspecto específico ${ }^{37}$, asociado también a las acusaciones de magia que él refiere.

35 Alsina, Op.cit. 34-39.

$36 \mathrm{El}$ asunto en realidad es algo más complejo, ya que Amiano sintetiza estas ideas. Para un análisis algo más acabado, Alsina, Op. cit., 60-65.

37 Barnes, Timothy, Ammianus Marcelinus and the Representation of the Historical Reality, New York, Cornell University Press, 1998, 158-161. 
En primer lugar, se define que existen cuerpos eternos, derivados del espíritu de los elementos, que cuentan con la capacidad de la adivinación de la cual se puede participar a través de distintas disciplinas. Estos poderes elementales, aplacados por rituales, son los que nos proporcionan los vaticinios, presididos por la diosa Themis, compañera de Zeus, que da a conocer lo que el destino determina para el futuro. La frase, que ha sido atribuida a una influencia del neoplatónico Porfirio en Amiano $^{38}$, nos ilustra dos elementos de la cosmología del autor: la existencia de poderes superiores que, por medio de Themis, dan a conocer el destino a los hombres, para ello el ritual y el conocimiento es clave. La adivinación está permitida en esta estructura cósmica, y si bien Amiano desea alejar la adivinación del ámbito de la magia anteriormente descrita, no deja de plantear que el ser humano debe actuar ritualmente mediante determinadas pautas para conocer el vaticinio. Esta teoría entonces, creemos no dista demasiado de la que se podría deducir de la práctica adivinatoria con trípode y plato con letras analizada anteriormente. En segundo lugar, atribuye a la acción directa de los dioses el que el vuelo y sonido de las aves o las entrañas de los animales sacrificados sirvan para conocer el futuro. También atribuye a la influencia del sol en nuestras mentes como explicación de las formas de adivinación píticas: según los físicos, enciende sus mentes y les permite adivinar como por boca de los dioses. Es la creencia entonces, de lo que ya apuntamos como un universo activo, unas divinidades que constantemente advierten a los hombres del porvenir. Amiano continúa dando formas válidas de conocer el futuro que caben dentro de esta categoría: sonidos de voces, truenos, relámpagos, estelas en el firmamento, sueños, todas bastante tradicionales.

Para finalizar nuestro análisis, creemos que no sólo Amiano sintetiza diversas tradiciones de adivinación (la única que no nombra en este momento es la astrología, de la que refiere en otro lugar como exacta, pero a la que quita valor por su determinismo $)^{39}$ sino que no deja de citar a autores reconocidos para su último punto: la adivinación se equivoca porque fallan los adivinos, pero eso no implica que sea falsa. Se sirve para ello de la teoría de los sueños de Aristóteles y de una cita Cicerón. Es decir, se recurre a autoridades probablemente reconocidas por las élites para defender la síntesis de prácticas que expone.

38 Barnes Op.Cit. 167.

39 Barnes, Op.Cit. 170. 
La lógica de la referencia a las autoridades es un punto en común con algunos excursos que podríamos llamar "científicos"en el autor. En XVII, 7, Amiano describe un terremoto que afectó a Nicomedia hacia 358 a.C. Pasada una descripción colorista y dramática del evento, se explican algunas interpretaciones antiguas sobre el fenómeno, sobre el cual los físicos de su tiempo aún no tienen acuerdo y siguen elucubrando. Comienza diciendo que los libros de rituales y pontificales no identifican a la divinidad causante, y luego refiere a las opiniones de autores como Anaxágoras, que en contraste a Aristóteles, afirmaría que la causa estaría en vientos que entran en la tierra y la agitan; la teoría de Anaximandro de grandes grietas abiertas por el calor o por copiosas lluvias, por donde penetrarían los vientos, haciendo referencia a Neptuno como quien agita y quiebra la tierra, para finalizar con una clasificación descriptiva de los terremotos derivada de Plinio el viejo ${ }^{40}$. Lo interesante entonces, es que un evento tan trágico y dramático es analizado más bien desde la perspectiva de un debate intelectual no concluido que desde una perspectiva de la acción de la divinidad en la tierra. La referencia a fuentes del ámbito religioso oficial es poco clara y se nombra a Neptuno y sus apelativos en asociación a una de las teorías explicitadas. Amiano así demuestra su erudición y su capacidad para utilizar diversas formas y niveles de explicación según sea necesario: nuestro autor desea explicitar algunas de las teorías al respecto del tema y reproduce cierto debate intelectual, sin relación con el esbozo de teología que antes referíamos. Esto que no implica el que este tipo de fenómenos no pueda ser considerado un presagio negativo: en otro pasaje de la misma obra (XXIII, 1,7) refiere que los expertos en presagios consideraron acertadamente un terremoto ocurrido en Constantinopla como anuncio nefasto para la expedición persa de Juliano, en conjunto con otros signos. Proponemos entonces, que para un hombre culto y erudito, el conocimiento que hoy podríamos llamar "científico", no se contradice con su creencia mágico/religiosa. Creemos que o bien se aplicaría en un plano distinto de la realidad (lo que hablaría de que no existe interacción entre ambos) o bien podría ser integrado a la cosmovisión descrita anteriormente. Para esto, vemos interesante hacer referencia a la teoría sobre las estrellas fugaces, insertada en los momentos anteriores a la muerte de Juliano en 363 (XXV, 2. 3-8) $)^{41}$. Luego de que Juliano observara el alejamiento del Genio del Imperio y preocupado "comenzó a suplicar a los númenes mediante los ritos

40 Según la traductora Harto de Trujillo, Plinio el Viejo, Nat 2, 201-206.

41 Para un fragmento similar, véase XXV, 10, 1-3, donde se explican los cometas según informan los físicos luego de asociarlos a presagios. 
apropiados para rechazar visiones", se sobresaltó ante un brillo, interpretado como la posible aparición de la estrella de Marte, que presagia la muerte. En ese momento, Amiano inserta algunos ejemplos del fenómeno del diaison o estrella fugaz, al que atribuye la visión: chispas de brillo celeste que se apagan, rayos que chocan con nubes y lanzan chispas o bien las iluminan formando un objeto de gran temperatura que se va desintegrando. Estas ideas, se han identificado por Harto del Trujillo como provenientes de Anaxágoras, Aristóteles y de Metrodoro de Quíos. Podemos ver entonces cómo en medio de las visiones y presagios del emperador se inserta una explicación física del fenómeno celeste, que luego será interpretada por unos adivinos etruscos (Etrusciharuspices) como una señal de que debía abstenerse del combate, tal como lo señalaban los libros Tarquicianos. Las súplicas de los arúspices fueron en vano, porque el emperador no quiso creerles y se levanta el campamento, llevándonos a la última batalla del emperador. En este caso, creo que queda claro que las teorías físicas pueden convivir con las atribuciones sacras de los signos celestes. Las posibles explicaciones a los fenómenos no alteran su significado y sentido, ni los despoja de su efectividad como presagios interpretables por expertos.

\section{IV.- El cuadro de las representaciones (una propuesta)}

Habiendo pasado por el análisis de las prácticas y de las teorías, es hora del balance sobre nuestra problemática, sintetizando la teoría expuesta y el análisis de Amiano realizado. ¿Cuál es el cuadro de las representaciones sobre la magia y lo sobrenatural que podemos extraer?

En primer lugar, creemos que es posible sostener que los actos definidos desde la teoría como mágicos, Amiano los comprende con ciertos matices: los encantamientos terapéuticos son acercados a la esfera de la medicina (sin dejar de ser definidos como "encantamientos de viejas") y otro tipo de prácticas fuera de la esfera de la religión oficial, son clasificadas de forma negativa (artes secretas, artes malignas, veneficum) y castigables por la ley de forma justa. Por tanto, son consideradas una amenaza para el orden social y son distinguidas de las prácticas útiles y piadosas de la adivinación. Creemos que Amiano hace eco de la legislación contemporánea y es posible sugerir que las distinciones teóricas de religión y magia en el debate (lo colectivo v/s lo individual, lo público $\mathrm{V} / \mathrm{S}$ lo privado, lo coactivo y activo $\mathrm{v} / \mathrm{s}$ lo interpretativo y pasivo) se ven de alguna manera reflejadas en el vocabulario utilizado por Amiano. 
En segundo lugar, es posible percibir la existencia de prácticas rituales adivinatorias negativas practicadas por las élites imperiales y de un deseo de diversos personajes elitescos y populares de tener acceso a los conocimientos mágicos. El ritual adivinatorio del asunto de Teodoro también ilustra dos nociones teóricas esbozadas al inicio: la idea de la magia analógica/simpatética y de las cadenas verticales de influencia podrían ser parte del trasfondo teórico/ explicativo de este tipo ritual.

En tercer lugar, podemos notar un uso ideológico por parte de Amiano del concepto Magus, por cuanto se aplica no a los condenados por veneficum o por adivinación que termina en lesa majestad, sino que se refiere a los sacerdotes persas, retratados como practicantes de un culto y religión puras, una especie de paradigma para un pagano que espera la reconstrucción de la tradición en un contexto de cada vez mayor oficialización del cristianismo.

En cuarto lugar, el análisis del contexto judicial de las condenas por magia por parte de Amiano termina en general (aunque no siempre, como en el caso de Aproniano) llevado al plano del abuso de poder y la injusticia. Incluso procesos adecuadamente iniciados por actos que Amiano considera detestables, terminan en abusos, muertes y persecuciones, mostrando la injusticia de algunos emperadores. Este análisis, por un lado, se entiende por la postura del autor desfavorable a Constancio II y Valentiniano y favorable a Juliano, pero también, en relación con el punto anterior, porque Amiano tendría una visión de restauración del culto tradicional y del imperio, en donde la correcta interpretación y ritualización de las diversas señales de la divinidad, junto con la práctica de la justicia por parte del emperador permitirían el correcto desarrollo del imperio. Por esto defiende a Juliano de las acusaciones de magia que se le hacen y omite la referencia a la práctica de la teúrgia, pero también critica sus excesos y "superstización" ritual.

En quinto lugar, en esta lógica es que se entiende el principal esbozo teórico de nuestro autor sobre estas temáticas esta puesto en la adivinación. El autor se esfuerza por mostrar a este arte como útil y necesario, lejos de la homologación que hacen algunos con las nociones de magia condenadas por la ley, acercándolo entonces a una idea de práctica religiosa. En su teorización, Amiano hace referencia a casi todas las formas de adivinación tradicionales y plantea con fuerza, junto con Cicerón, que el error es fallo del intérprete, no señal de la inexistencia de la posibilidad de conocer el futuro. Amiano 
en su teología, postularía la intervención divina en la historia y su necesaria interpretación por los hombres, siendo la justicia una de las medidas por las cuales los dioses decidían el destino del imperio.

En sexto lugar, su explicación de las fuerzas que intervienen para posibilitar la adivinación, no deja de responder, aunque de forma incompleta o indirecta, a la noción de cadenas verticales de influencia y su posicionamiento de Themis como la divinidad que permite la revelación del futuro ha sido atribuido a una influencia neoplatónica, postura que ha colaborado con sus reflexiones al desarrollo de un misticismo relacionado con prácticas mágicas, en especial la teúrgia. Debemos remarcar eso si, que las citas neoplatónicas de Amiano son justamente de los pensadores que no habían profundizado en la teúrgia, ya que el antioqueno no comparte esa visión espiritual del círculo del emperador Juliano.

En séptimo lugar, Amiano no deja de dar cuenta de una erudición similar en las explicaciones científico/filosóficas de determinados fenómenos naturales como terremotos o estrellas fugaces. Es capaz de dar cuenta de los debates en la materia y ponerlos en interacción con un relato que otorga un valor de presagio a este tipo de eventos. Parecieran o ser planos diferenciados de explicación, o bien plantearse un solapamiento entre ambas posturas. Que las estrellas fugaces sea un fenómeno asociado a la interacción de la luz solar y las nubes, no implica negar que pueda tener determinado significado premonitorio y ser señal del designio divino.

Finalmente, creemos entonces que desde Amiano Marcelino podemos obtener una representación de la magia y lo sobrenatural en la cual existen planos distintos: Los fenómenos son explicables desde el debate de los entendidos con causas naturales variables, pero también dan cuenta de un esquema de pensamiento "teológico" que considera la acción de la divinidad en lo terrenal y determinadas acciones y conocimientos útiles para relacionarse con esas fuerzas y acciones. Ante esto, podemos notar que Amiano divide este tipo de prácticas en aquellas centradas en las formas tradicionales de adivinación, entendidas como útiles y legítimas y otro conjunto de prácticas que podríamos llevar a lo mágico, consideradas como negativas, secretas y malignas, dignas de ser reprimidas y controladas de forma justa y ecuánime. 


\section{REFERENCIAS BIBLIOGRÁFICAS}

ALSINA, JOSÉ. (1989) El neoplatonismo, síntesis del espiritualismo antiguo, Barcelona: Ed. Anthorpos.

BARNES, TIMOTHY. (1998) Ammianus Marcelinus and the Representation of the Historical Reality, New York: Cornell University Press.

CASTILLO GARCÍA, CARMEN, ALONSO DEL REAL, CONCEPCIÓN Y SÁNCHEZ, ÁLVARO (Traducción y edición). (2010) Amiano Marcelino, Historias I. libros XIV-XIX, Madrid: Editorial Gredos.

CHARTIER, ROGER. (1992) El Mundo como Representación. Historia Cultural: entre práctica y representación. Barcelona: Editorial Gedisa.

COLLINS, DEREK. (2008). Magic in the Ancient Greek World, Oxford: Blackwell Publishing.

DAVIES, JASON P. (2004). Rome's Religious History, Livy, Tacitus and Ammianus on their Gods, Cambridge: Cambridge University Press.

DEN BOEFT, JAN. (1999) "Pure Rites, Ammianus on the magus", Drijvers, J.W., Hunt, David, (Eds) The Late Roman World and its Historian. Interpretating Ammianus Marcelinus, Londres y New York: Routledge.

DICKIE, METTHEW, (2003).Magic and Magicians in the Greco-roman World, London and new York: Routledge.

DODDS, E. R. (1997) Los griegos y lo irracional. Madrid: Alianza Editorial. GARCÍA TEJEDOR, ESTHER C. (2002) Formas marginales de la racionalidad en las ciencias ocultas. Madrid: Departamento de Filosofía de la Facultad de Filosofía de la U.N.E.D.

GIL, LUIS, (2001) “Medicina, religión y magia en el mundo griego”, Cuadernos de filología clásica: Estudios griegos e indoeuropeos, $\mathrm{N}^{\circ} 11$. Madrid.

HARTO DE TRUJILlO, Ma LUISA, (traductor y editor) (2002) Amiano Marcelino, Historia, Madrid: Editorial Akal.

JODELET, DENISE. (1984) "La representación social: fenómenos, concepto y teoría.” En: Moscovici, Serge (Ed.). Psicología social. Tomo II, Pensamiento y vida social, psicología social y problemas sociales. Barcelona: Editorial Paidós.

LUCK, GEORG. (2006) Arcana Mundi: Magic and the Occult in the Greek and Roman Worlds. A Collection of Ancient Texts, Baltimore: John Hopkins University Press.

MARTÍN HERNÁNDEZ, RAQUEL, (2006) El orfismo y la magia, Madrid: Universidad Complutense de Madrid. 
MAUSS, MARCEL. 1999) “Esbozo de una teoría de la magia”, en: Sociología y Antropología, Madrid: Editorial Tecnos.

OTTO, BERND-CHRISTIAN, STAUSBERG, MICHAEL (Eds.). (2013) Defining Magic. A reader, Sheffield: Equinox Publishing.

PHILLIPS, C.R. III. (1991) "Nullum Crimen sine Lege: Sociotrligious Sanction son Magic", Faraone, Christopher, Obbink, Dirk, ( Eds.) Magika Hiera, Ancient Greek Magic \& Religion, New York y Oxford: Oxford University Press, 1991.

RUIZ GUADALAJARA, JUAN CARLOS. (2003) "Representaciones colectivas, mentalidades e historia cultural: A propósito de Chartier y el mundo como representación", Relaciones. Estudios de Historia y Sociedad, La Representación en las Ciencias Sociales, Vol. XXIV, 93. Madrid.

SANTOS YANGUAS, NARCISO (1976) "El pensamiento historiológico de Amiano Marcelino". Estudios Clásicos XX. Madrid.

SANTOS YANGUAS, NARCISO (1979) "Presagios, adivinación y magia en Amiano. Marcelino", Helmantica 30. Madrid.

WOODMAN, A.J (Ed.). (2009) The Cambridge Companionto Tacitus. Cambridge: Cambridge University Press. 